\title{
Fenocopia del síndrome de Larsen asociado al uso de misoprostol: reporte de caso
}

\author{
Phenocopy of Larsen syndrome associated \\ with misoprostol use: A case report
}

\section{María A. Acosta-Aragón PhD', Gloria E. Martínez-Orozco MD², Gustavo A. Ángel-Ángel MD³, Annie C. Lasso-Torres $M D^{3}$}

\begin{abstract}
Resumen: el misoprostol es un análogo de la prostaglandina E1 con diversas utilidades terapéuticas incluyendo el tratamiento de la úlcera péptica. En el campo de la obstetricia es ampliamente utilizado para la inducción del trabajo de parto en escenarios específicos, abortos médicos e incluso emergencias obstétricas como el sangrado posparto. Su amplia distribución en el mercado farmacéutico ha llevado a que sea usado de manera indiscriminada con fines abortivos, desconociendo su potencial teratogénico durante la gestación. En este manuscrito se presenta el caso de un recién nacido, hijo de madre de 17 años, expuesto prenatalmente a misoprostol en dosis de $1.000 \mathrm{mcg}$ vía vaginal y $1.800 \mathrm{mcg}$ vía oral entre las semanas cuatro y 16 de gestación, que presentaba marcadas malformaciones articulares clínicamente compatibles con el síndrome de Larsen, entidad caracterizada por la presencia de dislocaciones de cadera, rodilla y codos, y deformidades en pie equino varo; además de hipertelorismo, frente prominente y puente nasal deprimido. Después de un estudio clínico y paraclínico se descartaron las posibles entidades genéticas y se demostró que las anomalías presentadas eran una feno-
\end{abstract}

\footnotetext{
${ }^{1}$ Médica, MSc en Biología, PhD en Genética de Poblaciones Humanas y Genética Forense. Integrante, Grupo de Investigación Lactancia Materna y Alimentación Complementaria, Docente Departamento de Pediatría, Facultad de Ciencias de la Salud, Universidad del Cauca. Popayán, Colombia. Correo electrónico: morin1924@gmail.com 2 Médica, Especialista en Pediatría y en Neonatología. Profesora Departamento de Pediatría, Facultad de Ciencias de la Salud, Universidad del Cauca. Coordinadora Unidad de Neonatología, Hospital Universitario San José. Popayán, Colombia.

${ }_{3}$ Médicos internos, programa de Medicina, Facultad de Ciencias de la Salud, Universidad del Cauca. Popayán, Colombia.

Conflicto de intereses: los autores declaran que no tienen conflicto de intereses Medicina \& Laboratorio 2016; 22: 191-198

Módulo 21 (Casos clínicos), número 16. Editora Médica Colombiana S.A. $2016^{\circ}$

Recibido el 02 de febrero de 2016; aceptado el 04 de abril de 2016
} 
copia del síndrome de Larsen causadas por el efecto teratogénico del misoprostol. En conclusión, el misoprostol es un medicamento teratogénico contraindicado durante el embarazo, que causa un amplio espectro de anomalías congénitas que producen fenocopias de diversas entidades genéticas. Esta situación hace que el paciente expuesto requiera un abordaje y estudio adecuado para llegar a un diagnóstico etiológico correcto que lleve a la mejor conducta terapéutica, con manejo inter y multidisciplinario.

Palabras clave: anomalías congénitas, síndrome de Larsen, fenocopia, misoprostol, teratógenos, embarazo.

Abstract: Misoprostol is an analogue of prostaglandin E1 with various therapeutic utilities, including treatment for peptic ulcer. In the obstetrics field is widely used for induction of labor in specific scenarios, medical abortions, and even obstetric emergencies, such as postpartum bleeding. Its wide distribution in the pharmaceutical market has facilitated another indiscriminate uses like non-medical abortion, ignoring their teratogenic potential during gestation. In this manuscript, it present the case of a newborn, born to a mother of 17 years, who was exposed prenatally to a misoprostol dose of $1,000 \mu \mathrm{g}$ by vaginal route and $1,800 \mu \mathrm{g}$ per mouth, between weeks four and 16 of gestation, that showed marked articular malformations clinically compatible with Larsen syndrome. This entity is characterized by the presence of dislocations of the hip, knee and elbows, deformities in equine foot Varus, in addition to hypertelorism, prominent forehead, and depressed nasal bridge. After a clinical study are discarded the possible genetic entities and it was demonstrated that the abnormalities were a imitation of Larsen syndrome caused by the teratogenic effect of misoprostol. In conclusion, misoprostol is a teratogenic drug contraindicated during pregnancy that causes a broad spectrum of congenital abnormalities that can cause imitation of several entities of genetic origin. This situation makes that exposed patient requires an appropriate approach and clinical study to reach a correct a etiological diagnosis, leading to a better therapeutic approach with an inter and multidisciplinary management.

Key words: Congenital abnormalities, Larsen syndrome, phenocopy, misoprostol, teratogens, pregnancy.

Acosta-Aragón MA, Martínez-Orozco GE, Ángel-Ángel GA, Lasso-Torres AC. Fenocopia del síndrome de Larsen asociado al uso de misoprostol: reporte de caso. Medicina \& Laboratorio 2016; 22: 191-198.

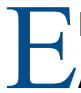
I misoprostol es un análogo sintético de la prostaglandina E1, aprobado por la Administración de Medicamentos y Alimentos (FDA; del inglés, Food and Drug Administration) para la prevención y el tratamiento de la úlcera gástrica asociada al uso de antiinflamatorios no esteroideos [1]. Además, es utilizado en el campo de la obstetricia para la inducción del trabajo de parto en escenarios específicos, abortos 
médicos e incluso emergencias obstétricas como el sangrado posparto [2].

La guía terapéutica sobre el uso de sustancias en el embarazo publicado por la FDA considera este medicamento como categoría $X$ debido a su efecto deletéreo observado en estudios controlados y observacionales realizados en animales o humanos, en los que su potencial teratogénico sobrepasa cualquier posible beneficio y contraindica de manera absoluta su uso [3].

La exposición prenatal a misoprostol ha sido asociada con la ocurrencia de anomalías congénitas tales como: microcefalia, defectos de la pared abdominal, artrogriposis, síndrome de Moebius, meromelia, sindactilia, afección de los pares craneales, holoprosencefalia, entre otras [4]. Algunas investigaciones con diseño de casos y controles han corroborado la asociación entre la exposición al misoprostol y la aparición de diferentes anomalías congénitas como las ya descritas [5].

El mecanismo de toxicidad del misoprostol durante la gestación no ha sido dilucidado en su totalidad debido a la similitud entre los defectos observados después de insultos por la hipoxia y aquellos observados en niños expuestos al medicamento. Una hipótesis considera que el fármaco causa una disrupción del desarrollo en una etapa embrionaria altamente dependiente de oxígeno, que puede ser producida por atrapamiento de la sangre fetal en la placenta por contracciones uterinas o por un efecto vasoconstrictor directo sobre las arterias uterinas [6].

Estadísticamente se ha asociado la exposición a misoprostol en el primer trimestre de embarazo con un aumento en el riesgo de la ocurrencia de múltiples casos de anomalías congénitas; incluso, su uso inadecuado representa un problema de salud pública en Colombia por diversos motivos [7]. En este manuscrito se presenta el caso de un paciente expuesto prenatalmente al misoprostol quien desarrolló anomalías secundarias al efecto teratógeno del mismo, cuyas características simulaban el síndrome de Larsen.

\section{Caso clínico}

Paciente masculino de un día de vida, producto del primer embarazo no programado de una madre estudiante universitaria de 17 años de edad y un padre agricultor de 23 años de edad, quienes proceden del área rural del municipio La Sierra del departamento del Cauca (Colombia). Presentación podálica con cesárea a las 33 semanas, prueba de Apgar 6-8-9.

Hospitalización en la Unidad de Cuidados Intensivos (UCI) neonatal por prematurez y síndrome de dificultad respiratoria. Se interconsulta al servicio de Genética Clínica por la presencia de luxación congénita de múltiples articulaciones. Como antecedente de importancia se encuentra que la madre ingirió como abortivo 
misoprostol en dosis de 1.000 mcg vía vaginal y 1.800 mcg vía oral entre las semanas cuatro y 16 de gestación.

Al examen físico se encuentra un paciente con peso de $1.710 \mathrm{~g}$, talla de $48 \mathrm{~cm}$, perímetro cefálico de $34 \mathrm{~cm}$, perímetro abdominal de $28 \mathrm{~cm}$, perímetro torácico de $27 \mathrm{~cm}$, distancia intercantal de $65 \times 25 \mathrm{~mm}$, Pabellones: $3 \times 1,5 \mathrm{~cm}$, distancia intermamilar: $8 \mathrm{~cm}$, relación segmento superior/segmento inferior: $0,7 \mathrm{~cm}$ y filtrum: $10 \mathrm{~mm}$. Se observa cráneo con turricefalia, facies aplanadas, cabello con línea de implantación alta anterior, frente prominente, pabellones de baja implantación, cejas escasas y pestañas escasas, hipertelorismo, puente nasal deprimido, tabique nasal recto, labios comisura bucal, paladar y úvula sin alteraciones (véase figura 1 ).
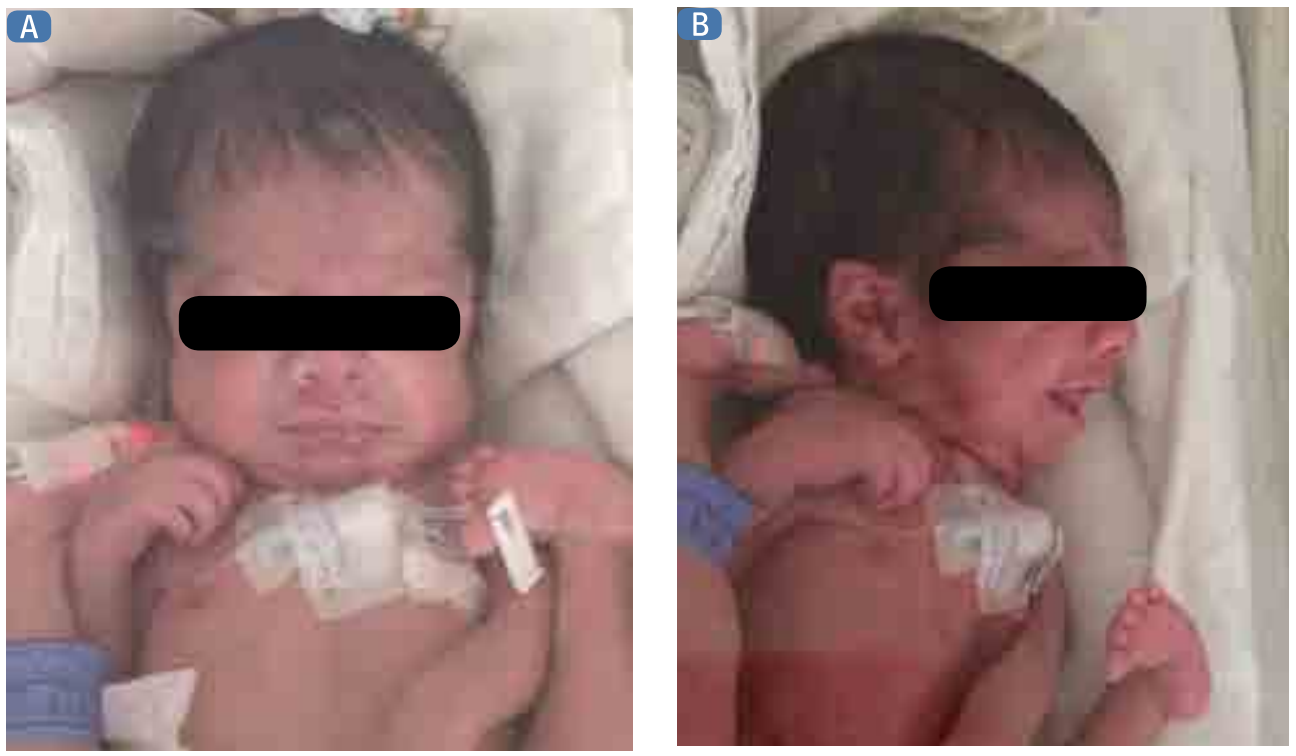

Figura 1. Cráneo con turricefalia, facies aplanadas, cabello con línea de implantación anterior alta, frente prominente, cejas y pestañas escasas, hipertelorismo, puente nasal deprimido, tabique alineado en la línea media (A) y orejas con línea de implantación baja (B). Imágenes reproducidas con el permiso de los padres.

Además, se observa cuello corto y grueso sin adenopatías y un examen pulmonar sin alteraciones. A nivel cardíaco se ausculta soplo sistólico grado I/IV, audible principalmente en foco aórtico y se observan glándulas mamarias de características normales no secretantes. En el abdomen se encuentra hernia inguinal izquierda sin signos de sufrimiento de asa, genitales externos masculinos en cuya bolsa escrotal no se palpa testículo izquierdo, ano perforado de localización usual, Ortolany-Barlow no realizable. En extremidades superiores e inferiores presenta hiperlaxitud, se observa flexión de caderas con hiperextensión de rodillas y pie equino varo bilateral; miembros superiores con braquidactilia y clinodactilia bilateral; además, pliegues de flexión distales en manos (véase figura 2). En cuanto al neurodesarrollo se encuentra alerta, reactivo a estímulos con reflejo palmoplantar y reflejo de búsqueda presentes. 


\section{Reporte de estudios prenatales}

Amniocentesis que concluye cariotipo 46XY. La ecografía obstétrica del tercer trimestre revela: «embarazo de 32 semanas, 1er día feto en presentación podálica, peso $1.932 \mathrm{~g}$, placenta lateral derecha grado II, pie equino varo bilateral, hueso nasal hipoplásico». Las pruebas para TORCH (toxoplasmosis, rubéola, citomegalovirus, herpes simple y VIH) maternas negativas.

\section{Reporte de estudios posnatales}

La radiografía abdominal total revela: «se observa normalidad en la distribución del gas intestinal, densidad hepática normal, se observa malformación en las extremidades inferiores con pie equino varo y signos de luxación congénita de cadera, las cuales se encuentran en abducción extrema, en la columna vertebral no se observan signos de espina bífida y los cuerpos vertebrales se observan de forma y tamaño normales» (véase figura 3 ).

A la ecografía abdominal se encuentra: «pielectasia bilateral mayor a la izquier$\mathrm{da}$, hiperecogenicidad renal que sugiere nefropatía incipiente». Al ecocardiograma: «evidencia de hipertensión arterial pulmonar leve en resolución, con presión pulmonar de $30 \mathrm{mmHg}$, no se observa ductus, persistencia del foramen oval permeable». A la ecografía transfontanelar: «asimetría de ventrículos laterales. Potenciales auditivos evidencian hipoacusia leve en oído derecho». A la tomografía axial computarizada (TAC) cerebral: «sistema ventricular normal. Septum Cavum pellucidum y septum Cavum vergae como variedades anatómicas, hipodensidades en la sustancia blanca debidas a mielinización incompleta por la edad del paciente, no se

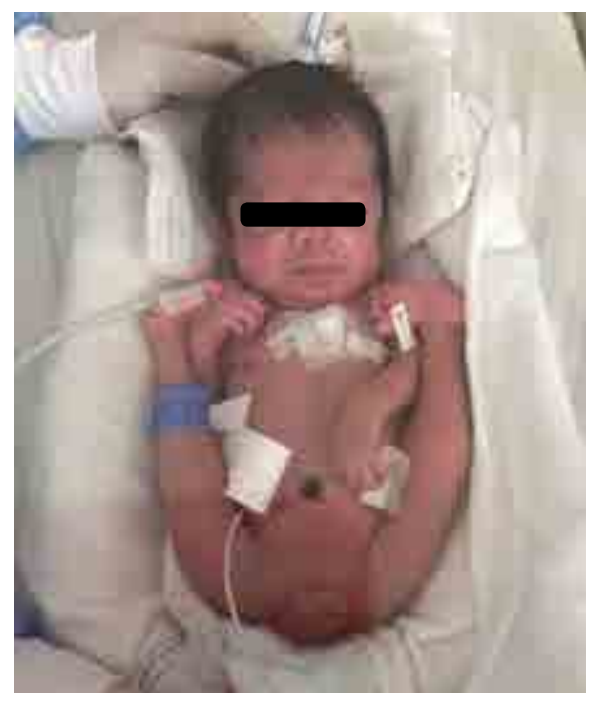

Figura 2. Extremidades superiores e inferiores presentan hiperlaxitud, se observa flexión de caderas con hiperextensión de rodillas y pie equino varo bilateral, miembros superiores con braquidactilia y clinodactilia bilateral; además, pliegues de flexión distales en manos Imágenes reproducidas con el permiso de los padres.

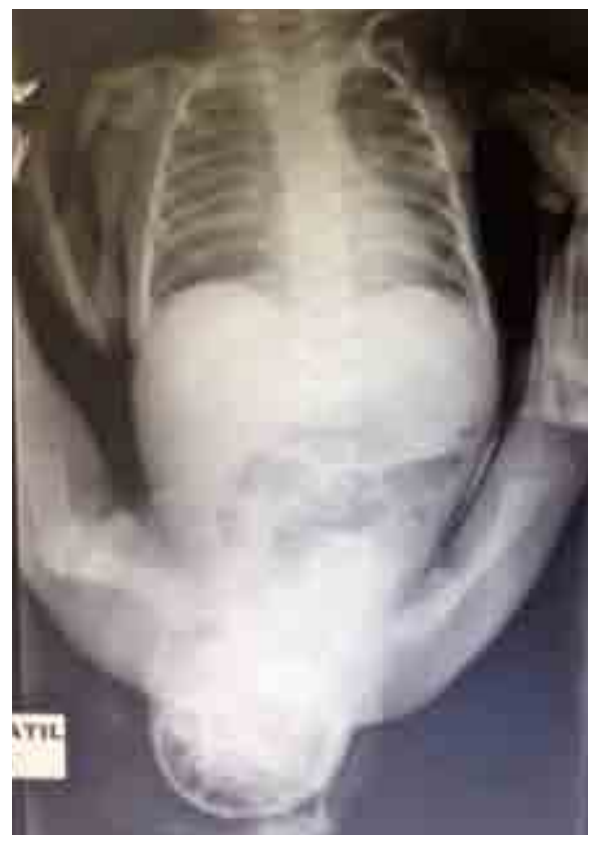

Figura 3. Radiografía abdominal total que muestra anomalías en las extremidades inferiores con pie equino varo y signos de luxación congénita de cadera, las cuales se encuentran en abducción extrema. Columna sin signos de espina bífida. 
evidencian calcificaciones patológicas ni lesiones isquémicas o hemorrágicas». A la ecografía inguino escrotal derecha se observa: «hernia inguinoescrotal derecha, criptorquidia izquierda». Las pruebas moleculares para síndrome de Larsen fueron negativas.

\section{Discusión}

Diversos textos y artículos científicos han evidenciado la relación que existe entre la exposición prenatal al misoprostol y la aparición de diversas anomalías congénitas [3-6]. Este articulo presenta el caso de un paciente en el que clínicamente se observan múltiples dislocaciones de cadera, rodilla y codos con deformidades en pies y anomalías craneofaciales consistentes en hipertelorismo, frente prominente, puente nasal deprimido y aplanado, características que en conjunto hicieron la impresión diagnóstica de un posible síndrome de Larsen.

El síndrome de Larsen es una entidad que fue descrita por primera vez en el año 1950 por Joseph Larsen, caracterizado clínicamente por la presencia de diversas dislocaciones articulares congénitas asociado a dimorfismos craneofaciales como hipertelorismo y puente nasal deprimido. Es, además, una enfermedad relativamente rara con una incidencia aproximada de 1:100.000 recién nacidos vivos [8], de etiología no muy clara, considerada como un posible desorden embrionario generalizado del tejido conectivo durante la gestación. Se han identificado en algunos pacientes alteración del locus 3p21.1-14 y microdeleciones en la proteína del citoesqueleto filamina B (FLNB), proteína citoplasmática que regula la comunicación intracelular entre la membrana y la red del citoesqueleto, conduciendo al adecuado desarrollo esquelético [9].

Inicialmente, en este paciente se sospechaba esta entidad; sin embargo, las pruebas moleculares diagnósticas fueron negativas. De ahí tuvo que realizarse un abordaje diagnóstico exhaustivo para descartar varias condiciones patológicas como parte del diagnóstico diferencial, entre ellas la disostosis húmero espinal, el síndrome de Ehlers-Danlos, la secuencia disruptiva de Moebius y la artrogriposis múltiple congénita [9]). Por las características clínicas la artrogriposis era otra posibilidad diagnóstica bastante factible; sin embargo, el paciente presentaba laxitud articular en forma de hipermovilidad, lo que lo diferencia de malas posiciones debidas a artrogriposis, en la cual las articulaciones se encuentran rígidas [10].

Por otra parte, se destaca en la historia clínica que el paciente estuvo expuesto a misoprostol durante su vida intrauterina y existen asociaciones de este medicamento y la aparición de la secuencia disruptiva de Moebius, cuya característica principal es la presencia de parálisis congénita bilateral de los nervios VI y VII, que conduce a una parálisis facial bilateral y del músculo recto externo. Dichas altera- 
ciones no fueron encontradas en nuestro paciente, pese a que estuvo expuesto al medicamento en el primer trimestre de vida intrauterina [11].

Luego de un ejercicio clínico y paraclínico ordenado y descartando otras posibles causas que explicaron el cuadro clínico del paciente se llegó a la conclusión de que las anomalías observadas fueron causadas por la exposición prenatal del paciente a los efectos teratogénicos del misoprostol, dichas alteraciones sin duda imitan fenotípicamente al síndrome de Larsen, lo que inicialmente fue un factor distractor para llegar a un diagnóstico adecuado.

\section{Agradecimientos}

Al paciente y su familia por permitirnos aprender sobre este caso y al Dr. Roberth Ortíz por su asesoría y dedicación.

\section{Bibliografía}

1. Norman JE, Thong KJ, Baird DT. Uterine contractility and induction of abortion in early pregnancy by misoprostol and mifepristone. Lancet 1991; 338: 1233-1236.

2. Abdel-Aleem H. Misoprostol for cervical ripening and induction of labour: RHL commentary. The WHO Reproductive Health Library. Ginebra, Suiza: World Health Organization; 2011.

3. Philip NM, Shannon C, Winikoff B. 2003. Misoprostol y teratogenicidad: Revisión de la evidencia. Informe de una reunión organizada por el Population Council New York, New York. 22 de mayo de 2002. http:// gynuity.org/downloads/mtg_rep_miso_teratogen_sp.pdf, accessed febrero 2016.

4. Cavieres MF. Toxicidad del misoprostol sobre la gestación: Revisión de la literatura. Rev Méd Chile 2011; 139: 516-523.

5. Vargas FR, Schuler-Faccini L, Brunoni D, Kim C, Meloni VF, Sugayama SM, et al. Prenatal exposure to misoprostol and vascular disruption defects: a case-control study. Am J Med Genet 2000; 95: 302-306.
6. Yip SK, Tse AO, Haines CJ, Chung TK. Misoprostol's effect on uterine arterial blood flow and fetal heart rate in early pregnancy. Obstet Gynecol 2000; 95: 232-235.

7. Isaza C, Saldarriaga W, Pachajoa H. Uso inadecuado de misoprostol. ¿Un problema de salud pública? Colomb Méd 2008; 39: 61-65.

8. Larsen LJ, Schottstaedt ER, Bost FC. Multiple congenital dislocations associated with characteristic facial abnormality. J Pediatr 1950; 37: 574-581.

9. Stossel TP, Condeelis J, Cooley L, Hartwig JH, Noegel A, Schleicher M, et al. Filamins as integrators of cell mechanics and signalling. Nat Rev Mol Cell Biol 2001; 2: 138-145.

10. Bonilla-Musoles F, Machado L, Bailao LA, Osborne N, García-Galiana S, Bailao TCRS, et al. Artrogriposis múltiple congénita (contracturas congénitas múltiples): revisión. Prog Obstet Ginecol 2002; 45: 150-156.

11. Ramírez-Cheyne JA, González P, Rojas I, Saldarriaga W, Isaza C, Pachajoa H. Reporte de un nuevo caso de síndrome Möbius y exposición prenatal a Misoprostol. Rev Cienc Salud 2015; 13: 505-511. 


\section{N Laboratorio ${ }^{\circledR}$ Clínico U Hematológico}

\section{Creemos en los sueños de todos los colombianos que llevan en la sangre confianza}

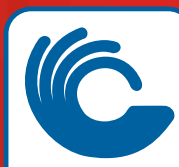

ISO 9001

\$icicontec

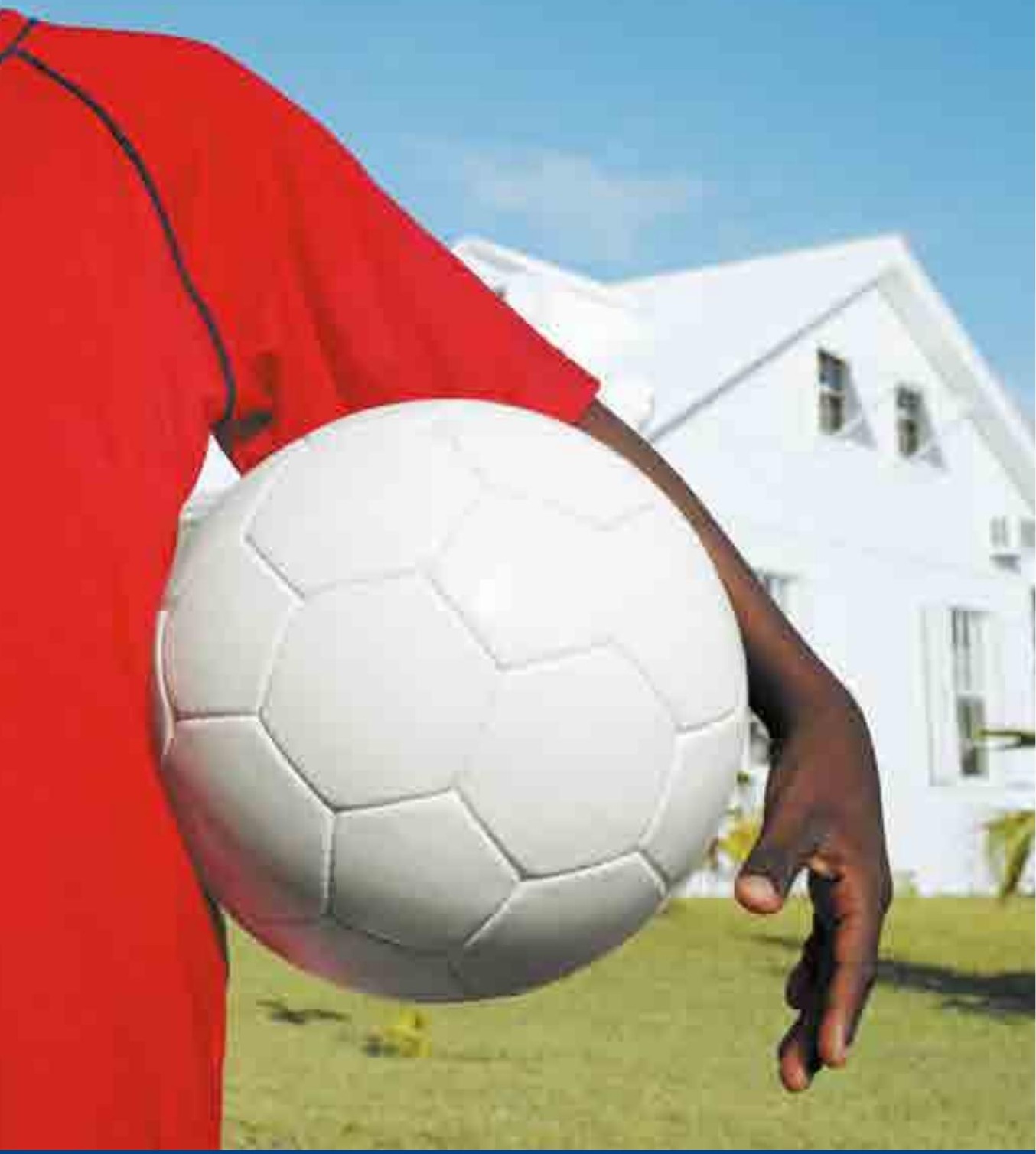

Sede Principal Poblado: Carrera 43C No. 5-33

Toma de Muestras: Centro Comercial Sandiego, Torre Norte, Piso 10, No. 1034 